\title{
Protecting sensitive constructions from tunnelling: the case of World Heritage buildings in Barcelona
}

\author{
A. LEDESMA* and E. E. ALONSO*
}

\begin{abstract}
Construction of the tunnel for the high-speed Madrid-Barcelona-France railway link across central Barcelona became a major technical and social challenge due to the impact of the tunnel on nearby historic buildings (two of them, the Sagrada Familia basilica and Casa Milà, being United Nations Educational, Scientific and Cultural Organization (Unesco) World Heritage structures). Protection of sensitive buildings from tunnelling-induced movements relied on the construction of a stiff pile wall, separating the tunnel from historic sites. This paper first presents a simplified procedure to analyse the wall-tunnel interaction in a straightforward manner. The main features of the tunnel, excavated by means of an earth pressure balance machine in tertiary clays and sands below the water table, are then described. Details of the design of the wall that was finally built are presented. Issues that were particularly important include the groundwater flow constraints and the use of small-strain soil stiffness properties to obtain realistic settlements. General criteria to design the protection wall are also presented. The good performance of the wall resulted in negligible tunnelling impact on the sensitive structures. The measured and predicted displacements are compared, suggesting that this type of solution is adequate to protect historic structures from tunnelling.
\end{abstract}

KEYWORDS: diaphragm \& in situ walls; ground movements; tunnels \& tunnelling

\section{INTRODUCTION}

Tunnelling in urban environments is a challenging task if ground displacements affect sensitive buildings and great efforts have been devoted to predict movements due to tunnelling in order to anticipate any damage to existing buildings (e.g. Attewell et al., 1986; Lee et al., 1992a, 1992b; Mair \& Taylor, 1997; Potts \& Addenbrooke, 1997; Loganathan \& Poulos, 1998; Burland et al., 2001; Mair, 2008; Bilotta et al., 2017). When a tunnel is planned next to a sensitive building, a stiff wall separating both structures may be a good option to reduce potential damage. This idea was proposed by Peck (1969) in the context of the observational method and has been used in practice in recent years. Oteo et al. (2007) and Gens et al. (2006) describe protective walls made of jet grouting columns, while Di Mariano et al. (2007) describe a wall comprising a row of piles. The reported experiences were positive in all cases.

However, the design of a wall separating a tunnel from a sensitive building is still far from routine. Most works on tunnel-pile interaction refer to the analysis of a deep pile foundation affected by a tunnel excavation (e.g. Chen et al., 1999; Kitiyodom et al., 2005; Lee \& Basset, 2006, 2007; $\mathrm{Mu}$ et al., 2012), but other contributions have focused on the general analysis of a diaphragm wall or a row of piles separating a tunnel and an existing building to be protected (Bilotta, 2008; Bilotta \& Stallebrass, 2009; Bilotta \& Russo, 2011). This paper deals with this specific application - when a wall is built before tunnel excavation as a method of reducing the impact of ground displacements on sensitive buildings. Such a wall does not have any initial load but, due to the displacements induced by the tunnel excavation and skin friction, it develops internal forces and bending

Manuscript received 5 March 2017; revised manuscript accepted 27 June 2017. Published online ahead of print 7 August 2017.

Discussion on this paper closes on 1 March 2018, for further details see p. ii.

* Universitat Politècnica de Catalunya, Barcelona, Spain. moments. Due to its stiffness, tunnelling-induced movements are reduced beyond the wall and therefore the impact on any nearby sensitive building is significantly reduced.

The focus of this paper is on vertical movements. First, an analysis of the tunnel-wall interaction is presented and a simplified procedure is used to visualise the main parameters controlling the interaction. The analysis, based on elasticity and analytical closed-form expressions, focuses on reduction of the settlement trough due to the wall. A real case involving the construction of a tunnel in Barcelona next to United Nations Educational, Scientific and Cultural Organization (Unesco) World Heritage buildings is then described. The protection of the sensitive buildings from tunnelling-induced movements was based on the construction of a stiff pile wall separating the tunnel from the historic sites. The wall, as well as the construction procedures described in the paper, resulted in negligible impact of the tunnel excavation on the sensitive buildings. Some general criteria for designing these types of walls are also presented.

\section{ANALYSIS OF TUNNEL-WALL INTERACTION}

Analysis of the interaction between a tunnel and a wall can be carried out by means of conventional finite-element (FE) or finite-difference analyses. However, simplified procedures are sometimes valuable in helping to understand the mechanisms involved in the interaction. With this aim, a two-dimensional (2D) plane-strain linear elastic and isotropic half-space was considered. Fig. 1 shows the basic geometry of the problem. The purpose of this simplified analysis is to estimate the settlement trough when a stiff wall is built at a distance $d$ from the tunnel axis. The method of superposition is used. When calculating soil displacements, they are a consequence of the movements generated by the tunnel excavation on the one hand and the forces induced by the wall on the other. Several approximate elastic solutions are available for a tunnel excavated in a plane-strain half-space. A force in the interior of the 2D half-space is known as the Melan problem, and expressions for stresses 


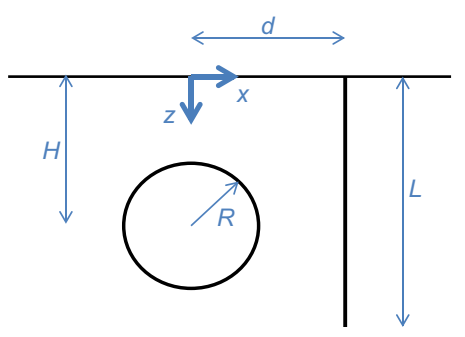

Fig. 1. Basic geometry of the tunnel-wall interaction problem

and displacements are also available. Although the geometries of the available solutions are different (one includes the tunnel and the other is a continuum half-space), the method of superposition is used here in order to estimate the settlement profiles.

\section{Effect of tunnel excavation}

Undrained conditions are assumed, which implies that the volume of material remains constant and therefore Poisson's ratio, $v$, is $0 \cdot 5$. Some closed-form expressions for surface settlements induced by tunnel excavation are available (e.g. Sagaseta, 1987). Most of these expressions are independent of soil stiffness as they are based on the constant-volume assumption. In this paper, the approximate formulae proposed by Loganathan \& Poulos (1998) are used as they provide a reasonable displacement field when compared with actual measurements. For the case $v=0 \cdot 5$, vertical displacement due to tunnel excavation is given by

$$
u_{z}=R^{2}\left(-\frac{z-H}{x^{2}+(z-H)^{2}}+\frac{z+H}{x^{2}+(z+H)^{2}}-\frac{2 z\left[x^{2}-(z+H)^{2}\right]}{\left[x^{2}+(z+H)^{2}\right]^{2}}\right) \varepsilon
$$

where $u_{z}(x, z)$ is the vertical displacement (positive downwards, as in Fig. 1), $R$ is the tunnel radius, $H$ is the depth of the spring line and $\varepsilon$ is the modified equivalent ground loss parameter, defined as

$$
\varepsilon=\varepsilon_{0} \exp \left[-\left(\frac{1 \cdot 38 x^{2}}{(H+R)^{2}}+\frac{0 \cdot 69 z^{2}}{H^{2}}\right)\right]
$$

where $\varepsilon_{0}$ is the equivalent average ground loss (i.e. the area of the surface settlement trough divided by the tunnel area). Equation (2) takes into account the oval-shaped ground deformation pattern around the tunnel section and results in a good estimation of ground movements.

\section{Effect of the lateral wall}

The effect of the lateral wall on soil displacements can be taken into account by considering the forces acting on the wall surface. A simple illustration of this interaction is presented in Fig. 2, where forces $P_{\mathrm{A}}$ to $P_{\mathrm{F}}$ and $P_{\text {tip }}$ represent the actionreaction forces between the soil and the wall. These forces tend to be directed upwards within the soil close to the wall and counterbalance the forces from the downward vertical movements induced by tunnelling. However, in the lower part of the wall, they may have a different direction, because tunnellinginduced soil displacements may tend to move upwards.

The problem of a load applied to an inner point in the $2 \mathrm{D}$ elastic half-space allows the effect of these forces to be estimated. Melan (1932) was the first to solve this problem in terms of stresses. Telles \& Brebbia (1981) later solved the same problem, found an error in the original work and extended the solution to the displacement field. However, some differences can be observed when comparing the

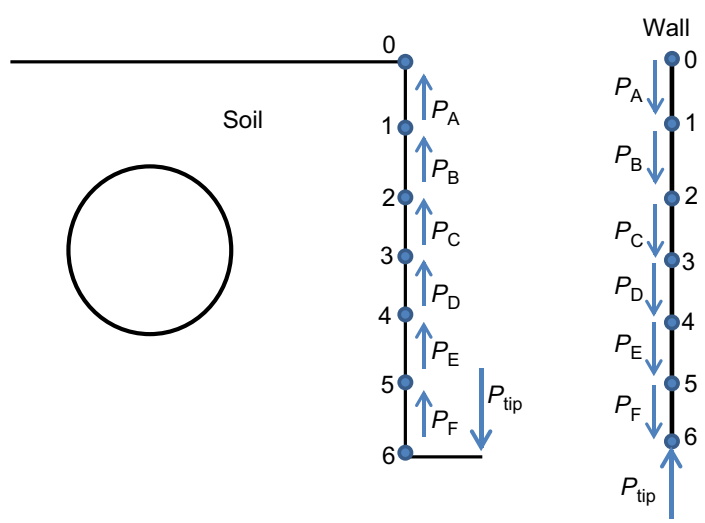

Fig. 2. Interaction forces between soil and wall

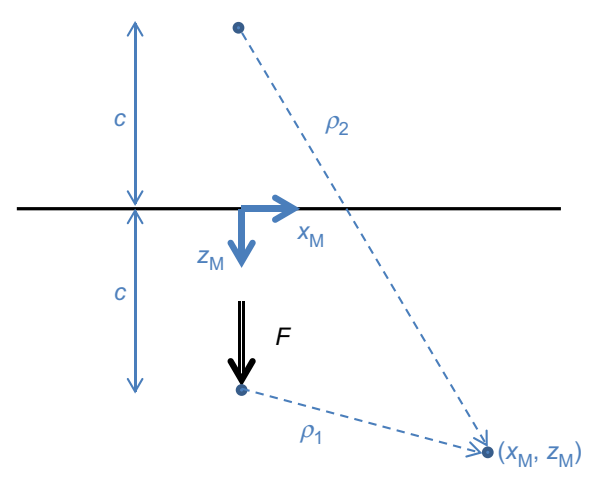

Fig. 3. Geometry of the 2D Melan problem

solutions provided by different authors. Here, the formulae presented by Sneddon (1951) and Verruijt \& Booker (2000) are used.

Figure 3 shows the geometry of the 2D Melan problem. The vertical displacement at point $\left(x_{\mathrm{M}}, z_{\mathrm{M}}\right)$ due to a force per unit length, $F$, is expressed as (assuming $v=0 \cdot 5$ )

$$
\begin{aligned}
u_{z}= & \frac{3 F}{2 \pi E_{\mathrm{S}}}\left[\ln \frac{1}{\rho_{2}}-\frac{1}{2} \ln \frac{\rho_{1}}{\rho_{2}}+\frac{x_{\mathrm{M}}^{2}}{2}\left(\frac{1}{\rho_{1}^{2}}-\frac{1}{\rho_{2}^{2}}\right)+\frac{\left(c+z_{\mathrm{M}}\right)^{2}}{\rho_{2}^{2}}\right. \\
& \left.+c z_{\mathrm{M}}\left(\frac{2\left(c+z_{\mathrm{M}}\right)^{2}}{\rho_{2}^{4}}-\frac{1}{\rho_{2}^{2}}\right)\right]+u_{0}
\end{aligned}
$$

where $E_{\mathrm{s}}$ is the Young's modulus of the soil, $c, \rho_{1}$ and $\rho_{2}$ are indicated in Fig. 3 and $u_{0}$ is an arbitrary constant. The displacement field (equation (3)) has two singularities - one at the point of load application and the other at infinity. However, relative displacements are finite. A simple procedure to deal with the singularities is to impose the condition that, at a certain distance from the load, the displacement is zero. It is convenient to impose this condition at a horizontal distance $x_{\mathrm{M}}=w$ on the ground surface (i.e. $\left.u_{z}(w, 0)=0\right)$, which allows the constant $u_{0}$ to be obtained. In this analysis, the vertical displacements on the ground surface and on the wall axis are of particular interest. For the case $x_{M}=0$ (wall axis), equation (3) becomes

$$
\begin{aligned}
u_{z}= & \frac{3 F}{2 \pi E_{\mathrm{S}}}\left[\ln \frac{\sqrt{c^{2}+w^{2}}}{c+z_{\mathrm{M}}}-\frac{1}{2} \ln \frac{\left|z_{\mathrm{M}}-c\right|}{\left(z_{\mathrm{M}}+c\right)}+1-\frac{c^{2}}{c^{2}+w^{2}}\right. \\
& \left.+c z_{\mathrm{M}}\left(\frac{1}{\left(c+z_{\mathrm{M}}\right)^{2}}\right)\right]
\end{aligned}
$$


and for the ground surface, where $z_{M}=0$, equation (3) reduces to

$$
u_{z}=\frac{3 F}{2 \pi E_{\mathrm{s}}}\left(\ln \frac{\sqrt{c^{2}+w^{2}}}{\sqrt{c^{2}+x_{\mathrm{M}}^{2}}}+\frac{c^{2}}{c^{2}+x_{\mathrm{M}}^{2}}-\frac{c^{2}}{c^{2}+w^{2}}\right)
$$

\section{Compatibility condition}

The interaction forces between the soil and the wall, $P_{\mathrm{i}}$, can be obtained by imposing compatibility of vertical movements at points 1, 2, 3 and so on (see Fig. 2). Movements in the soil can be estimated by combining the solution proposed by Loganathan \& Poulos (1998), expressed by equations (1) and (2), and the solution for the displacements induced by inner forces $P_{j}$. Movements of the wall can be readily calculated from the axial forces acting on it. For plotting purposes, the wall is divided into $n=6$ segments in Fig. 2. Each segment $j$ is loaded by a force $P_{j}$ acting at the segment midpoint $\left(P_{\mathrm{A}}, P_{\mathrm{B}}, P_{\mathrm{C}}, P_{\mathrm{D}}, P_{\mathrm{E}}\right.$ and $\left.P_{\mathrm{F}}\right)$. The vertical displacement of a point $i$ in the wall divided into $n$ segments can be computed as

$$
\left(u_{z}\right)_{i}=u_{n}+\sum_{j=i+1}^{j=n}\left[\frac{N_{j}}{E_{\mathrm{w}} A_{\mathrm{w}}} \frac{L}{n}\right]
$$

where $u_{n}$ is the displacement of the wall tip, $E_{\mathrm{w}}$ is the Young's modulus of the wall, $A_{\mathrm{w}}$ is the wall cross-section per unit length, $L$ is the vertical length (height) of the wall, $n$ is the number of segments considered and $N_{j}$ is the axial force in a particular segment $j$ (force per unit length). For the first segment, between points 0 and 1 , the axial force is $P_{\mathrm{A}}$, for the second segment the axial force is $P_{\mathrm{A}}+P_{\mathrm{B}}$ and so on. Vertical equilibrium must be considered when evaluating the reaction $P_{\text {tip }}$

$$
P_{\text {tip }}=\sum P_{j}
$$

The compatibility condition applied to point 0 to point $n-1$ is expressed as

$$
u_{z \text { tunnel }}+\sum_{j} u_{z \text { due to } P_{j}}=u_{z \text { structural wall }}
$$

for each point. The first term on the left-hand side of equation (8) is computed by means of equations (1) and (2), whereas the second term refers to the contribution of all interaction forces $\left(P_{\mathrm{A}}\right.$ to $P_{\mathrm{F}}$ and $\left.P_{\text {tip }}\right)$. The term on the right-hand side of equation (8) is computed from equation (6).

All the equations can be written in dimensionless form, thus reducing the number of variables involved. Here, the dimensionless variables are $Z=z / R, X=x / R, U_{z}=u_{z} / R$, $\mathcal{P}=P / E_{\mathrm{s}} R$. It can be shown that equation (8), written for each point, depends only on $\varepsilon_{0}$ and the dimensionless variables

$$
\begin{aligned}
& \Pi_{1}=H / R \\
& \Pi_{2}=d / R \\
& \Pi_{3}=L / R \\
& \Pi_{4}=E_{\mathrm{s}} R / E_{\mathrm{w}} A_{\mathrm{w}}
\end{aligned}
$$

Equation (8) applied at each point provides a linear system of $n$ equations with $n$ unknowns (the corresponding interaction forces at each segment). The displacements produced by these forces are then superposed onto the movements derived from the Loganathan \& Poulos (1998) solution to obtain the final soil displacements.

\section{Analysis}

Figure 4 shows the settlement trough for a 'greenfield' case and for several cases involving walls of different vertical

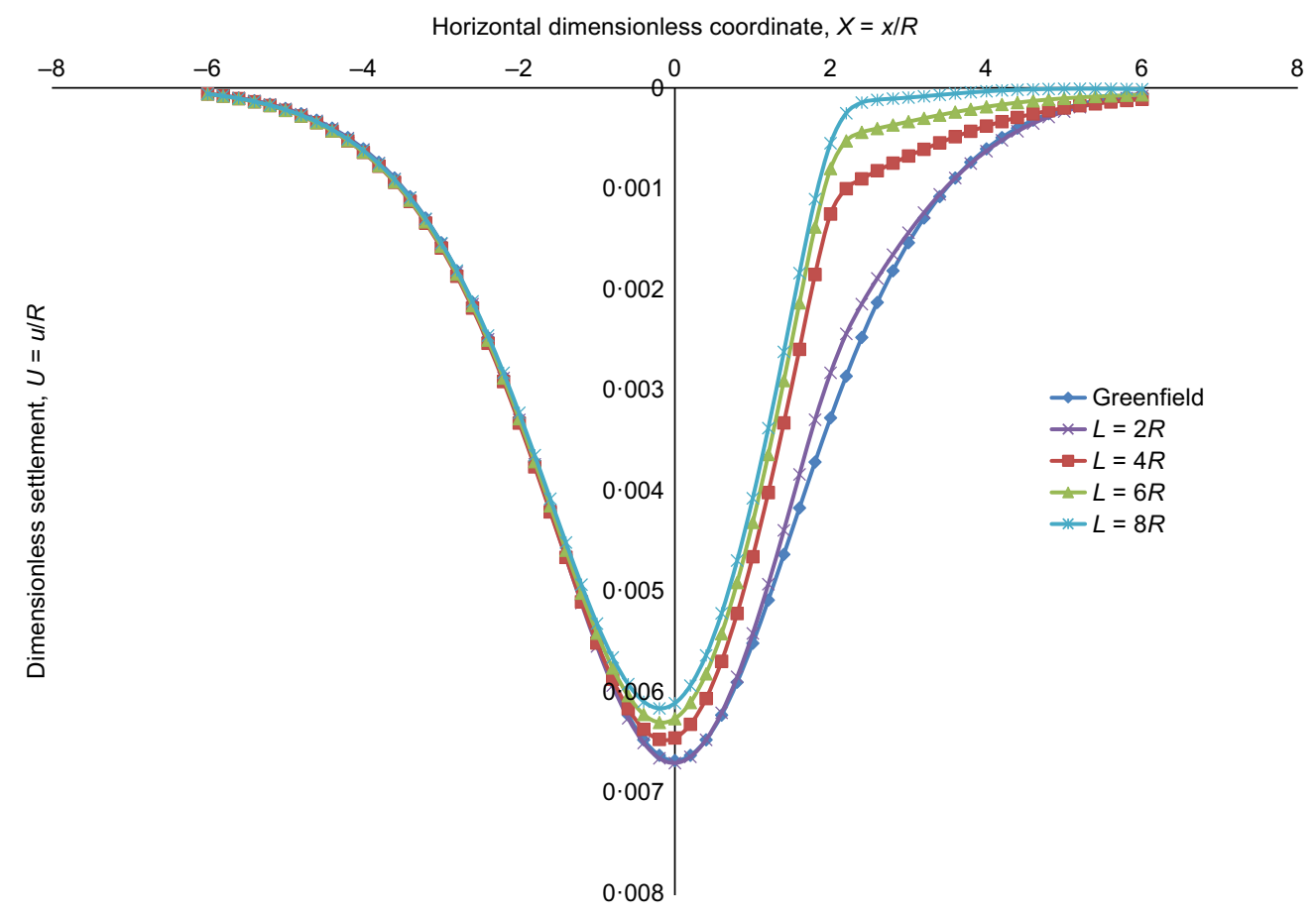

Fig. 4. Effect of wall vertical length, $L$, on the settlement trough using the simplified procedure: $\Pi_{1}=3, \Pi_{2}=2, \Pi_{4}=0 \cdot 0025$ and $\varepsilon_{0}=1 \%$ 
length $(L)$. The remaining dimensionless variables correspond to a base case with $\Pi_{1}=3, \Pi_{2}=2, \Pi_{4}=0.0025$ and $\varepsilon_{0}=1 \%$. The value of $\Pi_{4}$ would correspond to a two-lane railway tunnel in a stiff soil with $R=5 \mathrm{~m}, E_{\mathrm{s}}=100 \mathrm{MPa}$, $E_{\mathrm{w}}=200 \mathrm{GPa}$ and $A_{\mathrm{w}}=1 \mathrm{~m}^{2} / \mathrm{m}$.

To quantify the efficiency of the wall, $\eta$, the equation proposed by Bilotta \& Russo (2011)

$$
\eta=\frac{S_{\text {ref }}-S_{\mathrm{bw}}}{S_{\text {ref }}}
$$

is adopted, where $S_{\text {ref }}$ is the reference greenfield ground surface settlement and $S_{\mathrm{bw}}$ is the settlement immediately

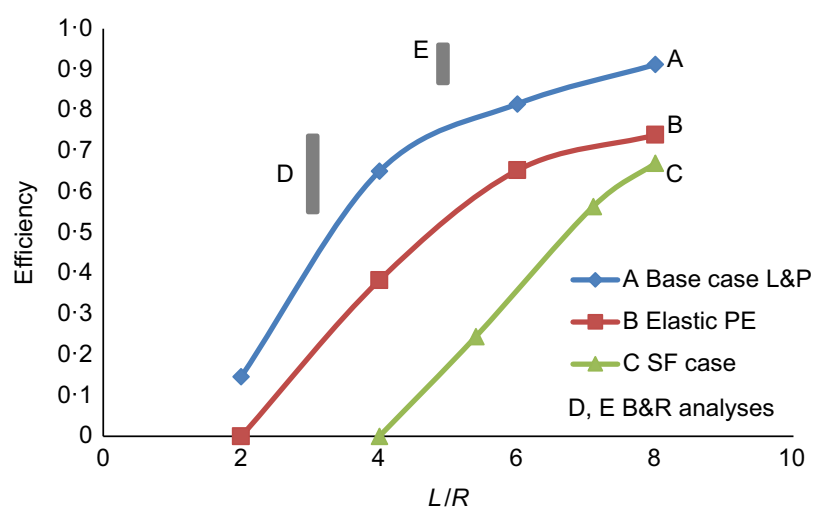

Fig. 5. Efficiency of the wall as a function of wall length (in dimensionless form). Curve $A$ is based on the simplified procedure (Loganathan \& Poulos, 1998) described in the paper for the base case. Curve B was calculated from an elastic FE analysis for the base case geometry. Curve $\mathrm{C}$ corresponds to application of the simplified procedure to the Sagrada Familia geometry and soil properties. Zones $D$ and $E$ correspond to the range of efficiencies computed by Bilotta \& Russo (2011) for volume losses ranging from $0.5 \%$ to $2 \cdot 5 \%$; $\mathrm{D}$ is for $L / R \approx 3$ and $\mathrm{E}$ is for $L / R \approx 5$ behind the top of the wall. A value $\eta=0$ implies the wall has no effect, while $\eta=1$ (or $100 \%$ ) indicates full suppression of movement. Curve A in Fig. 5 shows the efficiency of the wall computed for the cases depicted in Fig. 4. The efficiency is $65 \%$ for $L / R=4$. The wall tip in this case is located at the level of the tunnel invert. Therefore, lateral walls are efficient in reducing settlements when their tip level is located below the tunnel invert. This result is consistent with previous analyses of particular geometries carried out using the FE method (Bilotta \& Russo, 2011).

The working mechanism of the wall, regarding vertical displacements, mainly depends on the tip displacement. If the wall is too short, its tip will suffer significant displacements due to the tunnel excavation and this also will be the case for the top of the wall. Thus, increasing $L$ is very effective in terms of reducing settlements.

Symmetry of the settlement trough is lost when a lateral wall is built on one side of the tunnel. The maximum vertical displacement shifts away from the wall. This effect becomes more relevant as the wall length $L$ increases (Fig. 4).

The effect of wall stiffness on settlements is analysed in Fig. 6. Here, the dimensionless parameter $\Pi_{4}=E_{\mathrm{S}} R / E_{\mathrm{w}} A_{\mathrm{w}}$ was changed, keeping the remaining parameters constant as for the base case. The corresponding efficiency parameter defined in equation (10) is given by curve A in Fig. 7. It is clear that there is a certain value of the wall axial stiffness beyond which surface ground settlements do not change substantially. In other words, for very stiff walls (compared with soil stiffness), surface settlements are controlled by movement of the wall tip. In practice, it is more efficient to increase $L$, provided that a minimum axial stiffness is incorporated into the design of the wall.

The simplicity of the described procedure allows the effect of changing other variables on the pattern of settlements to be analysed. For instance, varying the wall-tunnel distance, $d$, does not substantially change the efficiency of the wall, as shown in Fig. 8.

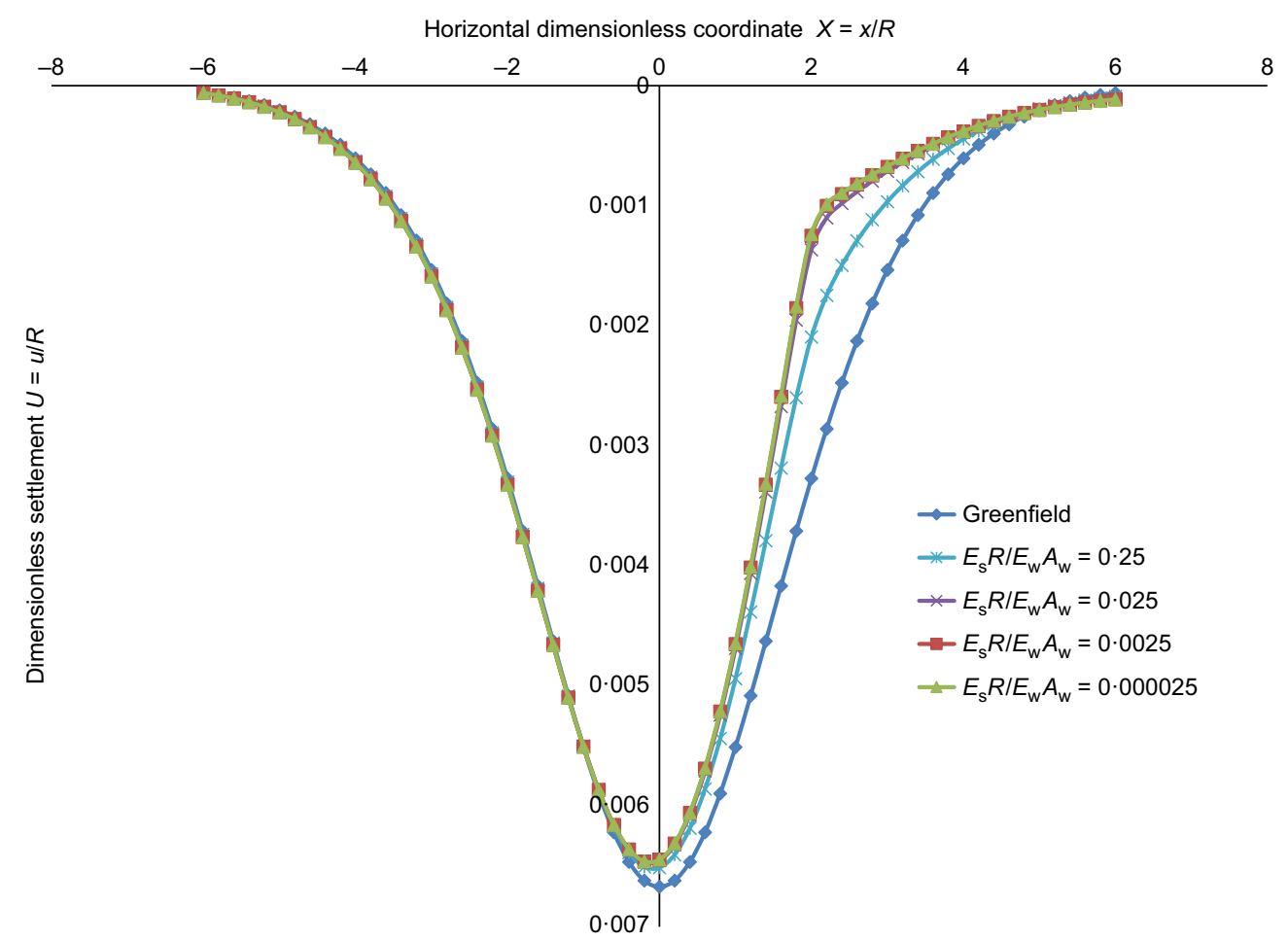

Fig. 6. Effect of soil-wall relative stiffness on the settlement trough 
Assumptions and validity of the results

The simplified procedure described in this paper can be extended to take into account horizontal movements and normal forces acting on the wall. In this case, the relative

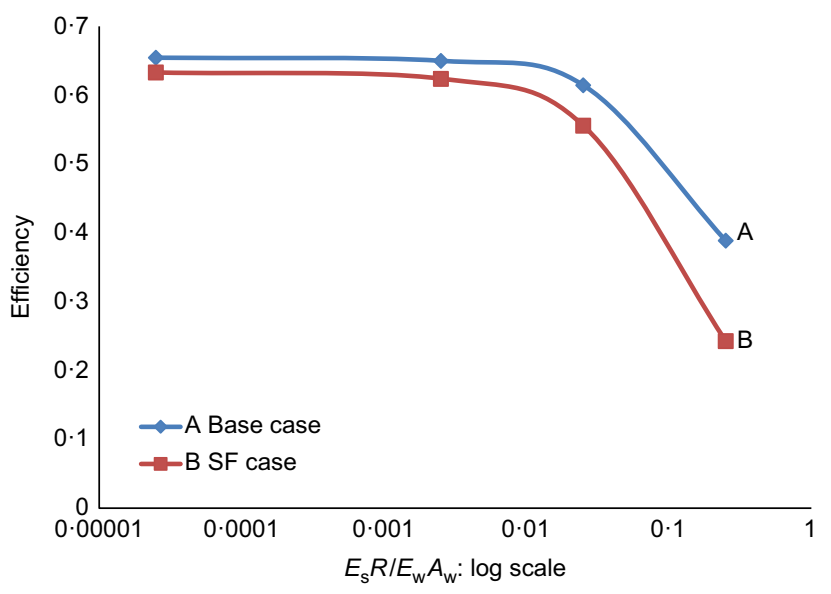

Fig. 7. Efficiency plotted against stiffness ratio for the base case (curve A) and the Sagrada Familia geometry (curve B)

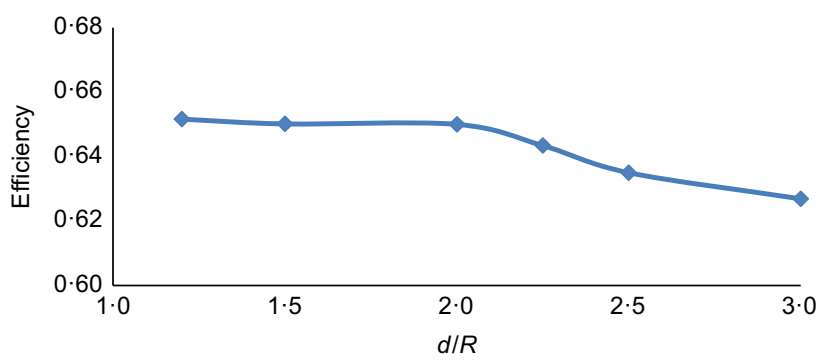

Fig. 8. Efficiency as a function of the wall-tunnel distance, $d$, for the base case $(H I R=3, L I R=4$, stiffness ratio $=0 \cdot 0025)$ stiffness is defined by the dimensionless parameter $E_{\mathrm{s}} R^{3} / E_{\mathrm{w}} I_{\mathrm{w}}$, where $I_{\mathrm{w}}$ is the second moment of area of the wall per unit length $\left(\mathrm{m}^{4} / \mathrm{m}\right)$. The details of this extension are, however, outside the scope of this paper.

When the wall is made from piles, then an average value per unit length of $E_{\mathrm{w}} A_{\mathrm{w}}$ and $E_{\mathrm{w}} I_{\mathrm{w}}$ should be estimated, taking into account the separation between piles (Potts \& Zdravković, 2001).

The method described in this paper was also compared with a conventional FE analysis. When using elasticity in FE analyses, it is well known that boundaries have a strong influence on the pattern of displacements. Even if more sophisticated models are used, boundaries may determine the computed absolute displacements, in particular in cases far from failure conditions.

Figure 9 shows the settlement troughs obtained from a FE analysis using Plaxis 2D software (Brinkgreve et al., 2016). The mesh geometry involved a rectangle $160 \mathrm{~m}$ wide and $100 \mathrm{~m}$ deep, and a tunnel of $R=5 \mathrm{~m}$ and $H=15 \mathrm{~m}$. The soil was assumed to be elastic $\left(E_{\mathrm{s}}=10 \mathrm{MPa}, v=0.5\right)$. The properties of the wall were adopted to match the value of $\Pi_{4}=0.0025$, as for the base case considered previously. The wall-tunnel distance was $d=10 \mathrm{~m}$ and the wall length was changed from $L=10 \mathrm{~m}(L / R=2)$ to $L=40 \mathrm{~m}(L / R=8)$. In order to compare settlement troughs, the volume loss in the FE analysis was selected to obtain the same value of maximum vertical displacement as in the base case of the simplified procedure. Fig. 9 shows two greenfield curves (without a wall): one corresponds to the Loganathan \& Poulos (1998) expression (L\&P) and the other was obtained from Plaxis (elastic). As expected, the elastic trough extended settlements far away from the tunnel. This is the main reason why Loganathan \& Poulos (1998) modified the distribution of displacements, to match real data from field measurements.

Despite the differences in the greenfield curves, the trends in Fig. 4 (simplified solution) and Fig. 9 (FE) are similar. If the efficiency is computed for the FE case, curve B in Fig. 5 is obtained. Curves A and B in Fig. 5 show a rapid increase in efficiency with wall length. The efficiency depends not only

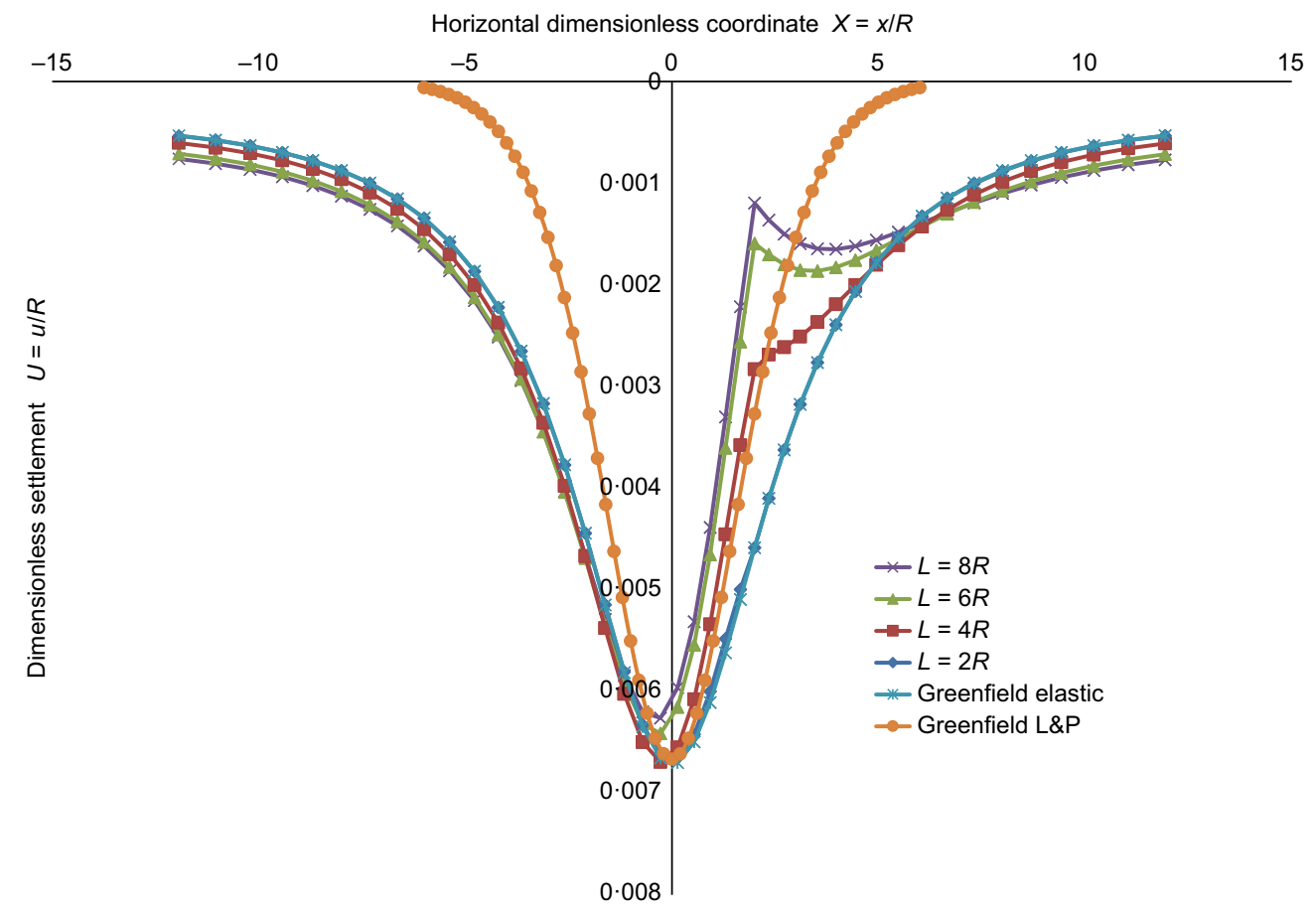

Fig. 9. Effect of wall length, $L$, on the settlement trough using FE elastic analysis 
on the parameter $L / R$, but also on the displacement of the wall tip. This is very sensitive to the lower boundary in the elastic FE analysis and to the Loganathan \& Poulos (1998) expression in the simplified procedure. If the wall tip is in a very stiff layer, settlement of the wall will be almost negligible and the efficiency will essentially reach $100 \%$. In general, the efficiencies obtained with the Loganathan \& Poulos (1998) solution are higher than those obtained from conventional FE elastic analysis (provided that the lower boundary is far from the wall tip) because the solution concentrates settlements above the tunnel.

Bilotta \& Russo (2011) presented numerical analyses computing the efficiencies of a pile wall as a function of pile spacing, $s / b$ ( $s$ being the space between pile centres and $b$ the pile diameter). Case $s / b=1$, relating to a contiguous pile wall, would correspond to a continuous diaphragm wall and the computed efficiencies in this case were about 0.6 for walls with $L / R \approx 3$ and about 0.9 for deep walls $(L / R \approx 5)$. The results of Bilotta \& Russo (2011) suggest that wall efficiency is not very sensitive to volume loss or stiffness ratio (in the case presented where wall bending stiffness was related to the soil modulus at $50 \%$ of ultimate load, $E_{50}$ ). These results are included in Fig. 5 for comparison. They are consistent with the results obtained using the simplified procedure; that is, volume loss affects all movements and interaction forces but has no influence on wall efficiency and wall stiffness (in this case $E_{\mathrm{w}} A_{\mathrm{w}}$ ) is not critical provided that a minimum value relative to soil stiffness is assured. However, the efficiencies obtained by Bilotta \& Russo (2011) are higher than those obtained using the simplified procedure presented here and the values corresponding to the elastic FE analysis are even smaller. This discrepancy may be explained by $(a)$ the constitutive model used by Bilotta \& Russo (2011) (the hardening soil model), where stiffness increases with depth, and $(b)$ the fact that the lower boundary was relatively close to the tunnel. Both aspects would contribute to reducing the settlement of the pile tip and therefore to improving the wall efficiency.

Wall efficiency also depends on the properties of the wallsoil interface (Bilotta, 2008). Smooth interfaces tend to concentrate displacements above the tunnel and decrease settlements beyond the wall. Therefore, the assumption of a rough interface is conservative from the point of view of efficiency. Implicitly, a rough interface is assumed in the simplified procedure and the elastic analysis presented earlier.

\section{CASE STUDY: PROTECTION OF WORLD HERITAGE BUILDINGS IN BARCELONA}

A tunnel was planned through central Barcelona as part of the high-speed railway connecting Madrid, Barcelona and the border with France. The new tunnel connects Sants and
Sagrera stations at two opposite ends of Barcelona, crossing a district developed at the beginning of the 20th century and famous for its modernist (Art Nouveau) architecture. Most of the existing buildings (5-8 storeys high) were designed with shallow footings and load-bearing walls. These structures are sensitive to differential foundation movements. The tunnel was designed to follow two main streets of about $20 \mathrm{~m}$ width within the district, Carrer de Provença and Carrer de Mallorca. Two structures facing these streets were particularly sensitive to ground displacements - Casa Milà (also called La Pedrera) and the Sagrada Familia basilica, both designed by the architect Antoni Gaudí and classified as World Heritage buildings. The basilica, initiated in 1882, is still under construction.

The dimensions of the Sagrada Familia and the proximity of one of its façades to the tunnel led to opposition to the railway project from basilica officials as they argued that the tunnel imposed an unacceptable risk to the historic building. The project became a controversial issue, even within the civil engineering community. Consequently, additional checks and controls by several external teams were carried out, including engineering firms (Rodríguez-Escribano \& Blanco-Zorroza, 2012), Unesco experts (Katzenbach et al., 2011) and the authors of this paper (Alonso \& Ledesma, 2015).

\section{Tunnel and soil description}

The tunnel is about $5.6 \mathrm{~km}$ long and the central part, about $5 \mathrm{~km}$ long, was built by means of a single earth pressure balance shield (EPB) manufactured by Herrenknecht AG. The tunnel has a boring diameter of $11.55 \mathrm{~m}$ and the lining includes seven $0.38 \mathrm{~m}$ thick reinforced concrete segments. The tunnel cover above the crown is about $25 \mathrm{~m}$ in the central part and crosses under a few existing metro lines and services, as shown in Fig. 10. The soil at this depth is basically a stiff Pliocene substratum described as an irregular sequence of sandy clay and clayey sand. Standard penetration test counts in this layer varied between 40 and 50, indicating a strong material. The upper limit of the Pliocene layer was irregularly eroded during the Quaternary era and a reddish soil was deposited on top. This soil is described as a sequence of silts, sands and clays, including some gravels and carbonate concretions. The Quaternary soils are unsaturated stiff materials; some of the silty clays may have been affected by calcium carbonate cementation. This Quaternary layer constitutes a good base for shallow foundations. Fig. 11 shows a simplified lithological profile.

The water level in this part of the city is about $15-16 \mathrm{~m}$ deep. Deep sandy layers below the tunnel had a piezometric head around $6 \mathrm{~m}$ higher than the value corresponding to the local water table, since they were connected to aquifers from

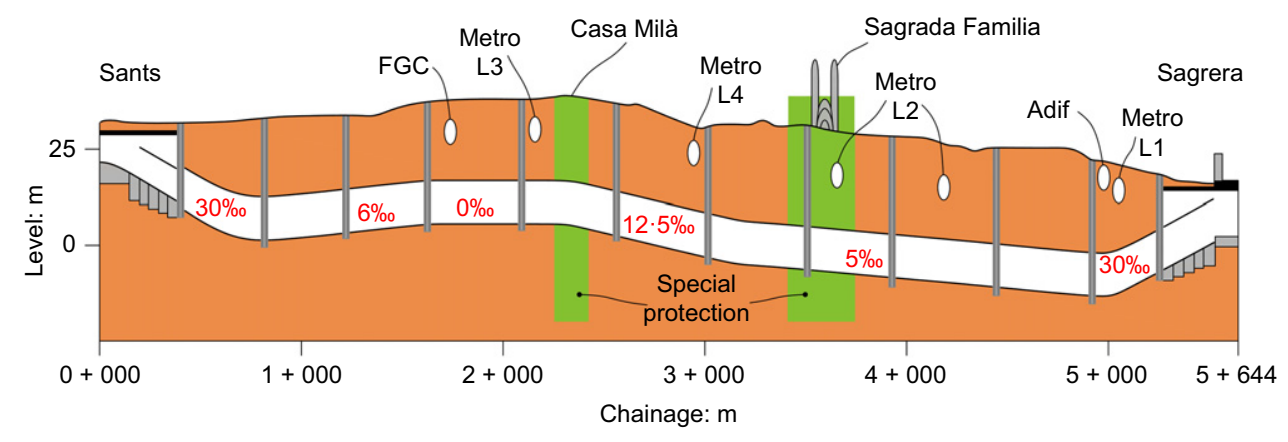

Fig. 10. Longitudinal profile of the tunnel 

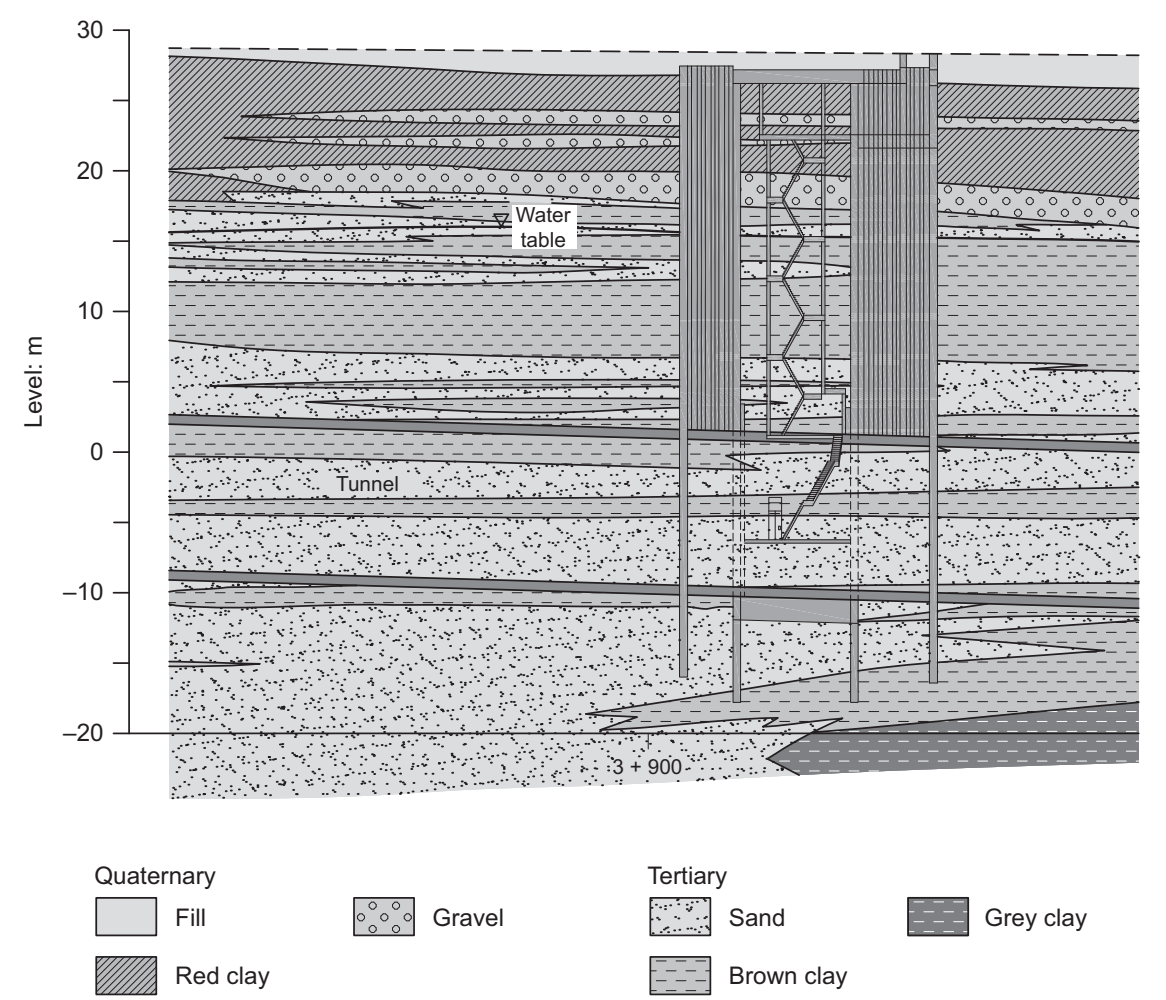

Fig. 11. Geotechnical profile in the area of a vertical shaft for EPB inspection, before approaching the Sagrada Familia basilica

the hills surrounding the city. The average soil water pressure at the spring line level was about $150 \mathrm{kPa}$. In addition, in the city there is a general groundwater flow through sandy units from the hills to the sea. The tunnel is perpendicular to this flow and concern was raised about its effects on the piezometric levels. Furthermore, the design of any lateral wall protecting sensitive buildings could also aggravate these effects. However, analyses of the groundwater flow in this context indicated that the tunnel did not constitute a significant barrier to the flow, due to the high permeability of the sandy layers. The protective wall was designed as a line of non-secant piles to allow for the passage of groundwater. Details of the groundwater analyses are described by Pujades et al. $(2014,2015)$.

Settlements induced by the tunnel excavation were a major concern. The annular gap between the lining and excavated ground was about $19 \mathrm{~cm}$ and it was continuously injected with quick-hardening grout through the back of the shield to reduce volume loss. Pressures in the EPB chamber were computed, taking into account soil-water conditions and local experience. In the zone close to the Sagrada Familia basilica, a target value of $243 \mathrm{kPa}$ was adopted for the pressure at the upper part of the chamber, which was slightly higher than typical values usually adopted due to the presence of sandy units below the water table. The risk of sudden erosion of the sand entering the EPB chamber was reduced by keeping the chamber almost full of spoil. In addition, the main variables of the EPB machine, usually controlled by the contractor within the EPB project and the client, were also transmitted to an external control unit where tunnel boring machine engineers compared online machine measurements with target values and checked the consequences of the tunnel excavation in terms of soil movements and pore water pressures. This online control was useful for keeping EPB operating variables quite constant and for providing additional support for decision making if necessary.
Description of the wall protecting sensitive buildings

A wall to separate sensitive buildings from the tunnel was designed for the Sagrada Familia basilica and Casa Milà. A similar design was used for both sites, but the geometry and conditions corresponding to the Sagrada Familia were taken as a base case for analysis, this being the most challenging scenario. The original design of the pile wall was based on previous experiences in the city during the excavation of metro tunnels (Gens et al., 2006; Di Mariano et al., 2007) and on FE calculations. Later papers published on this topic (Bilotta, 2008; Bilotta \& Russo, 2011) and the ideas presented in this paper were then used to check whether or not the original design was appropriate. In the end, the original design was maintained because it was essentially adequate and because any change would have been a controversial issue.

Figure 12 shows the geometry of the pile wall, the tunnel and the basilica, and Fig. 13 shows a photograph of the pile wall construction. The space available to build the wall was limited. The reinforced concrete piles were $1.50 \mathrm{~m}$ in diameter and $41 \mathrm{~m}$ long and were separated $2 \mathrm{~m}$ between axes (i.e. with a $0.5 \mathrm{~m}$ gap between them). Pile heads were connected by a cap beam, as shown in Fig. 12. In order to reduce pile cap displacements, a 'counterfort' block was designed adjacent to the pile capping beam. Verticality of the piles was checked prior to installing reinforcement and pouring concrete by means of an ultrasonic technique, because any error might cause the piles to be intercepted by the cutting head of the EPB machine. The barrier was extended well before and after the basilica's location, covering a total length of $230 \mathrm{~m}$.

The geometry of the pile wall constructed to protect Casa Milà was similar. The piles, $1.20 \mathrm{~m}$ in diameter and $37 \mathrm{~m}$ long, were separated by $1.70 \mathrm{~m}$ between axes. Fig. 14 shows a photograph of the piling works close to the façade of Casa Milà. Boring of the piles resulted in very small displacements (less than $1 \mathrm{~mm}$ ) of both structures. 


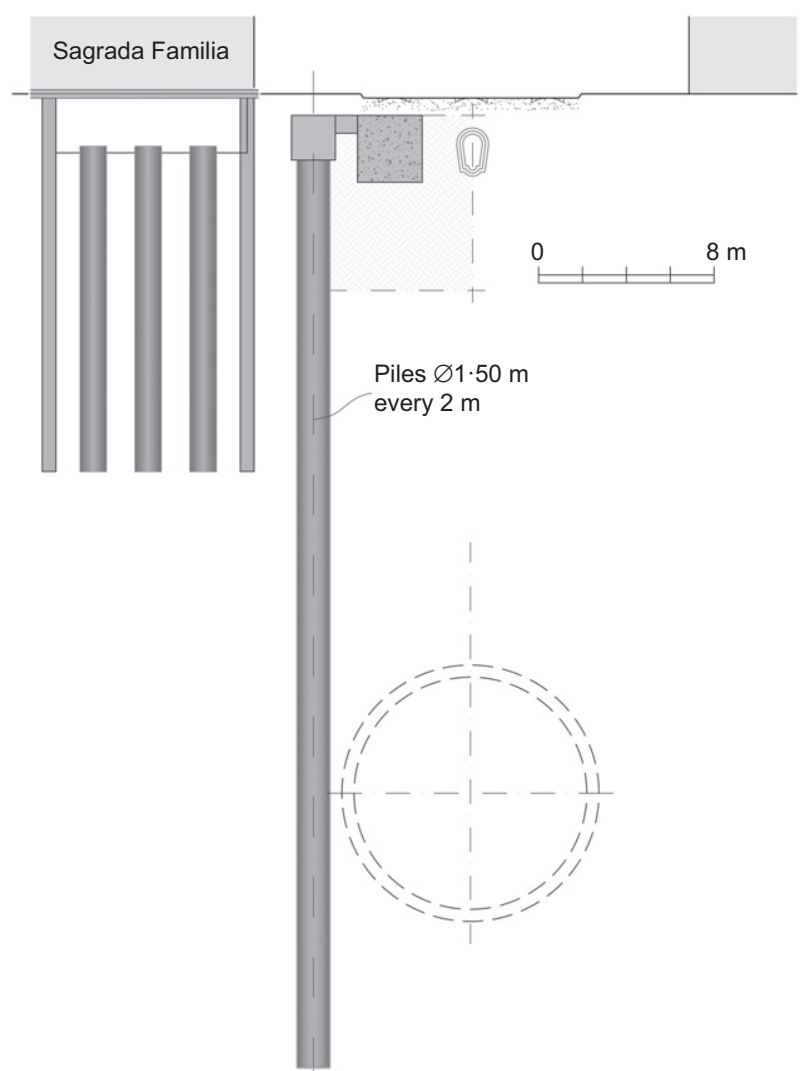

Fig. 12. Cross-section of the tunnel, the lateral pile wall and the Gloria façade of the Sagrada Familia basilica

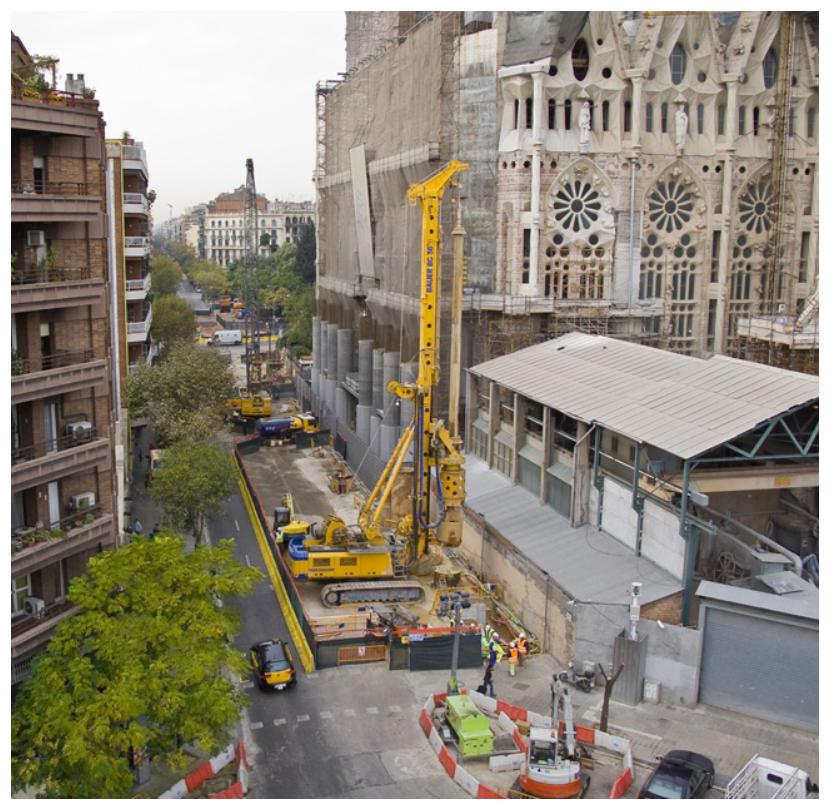

Fig. 13. Pile wall construction next to the Sagrada Familia

The geometry shown in Fig. 12 gives the dimensionless variables defined in equation (9) as $\Pi_{1}=H / R=5 \cdot 4$, $\Pi_{2}=d / R=1 \cdot 4$ and $\Pi_{3}=L / R=7 \cdot 1$. A value of $\varepsilon_{0}=1 \%$ was considered in order to compare this analysis with the previous base case. For the stiffness ratio, assuming $E_{\mathrm{s}}=30 \mathrm{MPa}, E_{\mathrm{w}}=30000 \mathrm{MPa}$ and $A_{\mathrm{w}}=1 \mathrm{~m}^{2} / \mathrm{m}$ resulted in $\Pi_{4} \approx 0 \cdot 006$. These values are different from the base case, which was assumed to have a more common geometry. Applying the simplified procedure presented earlier in the

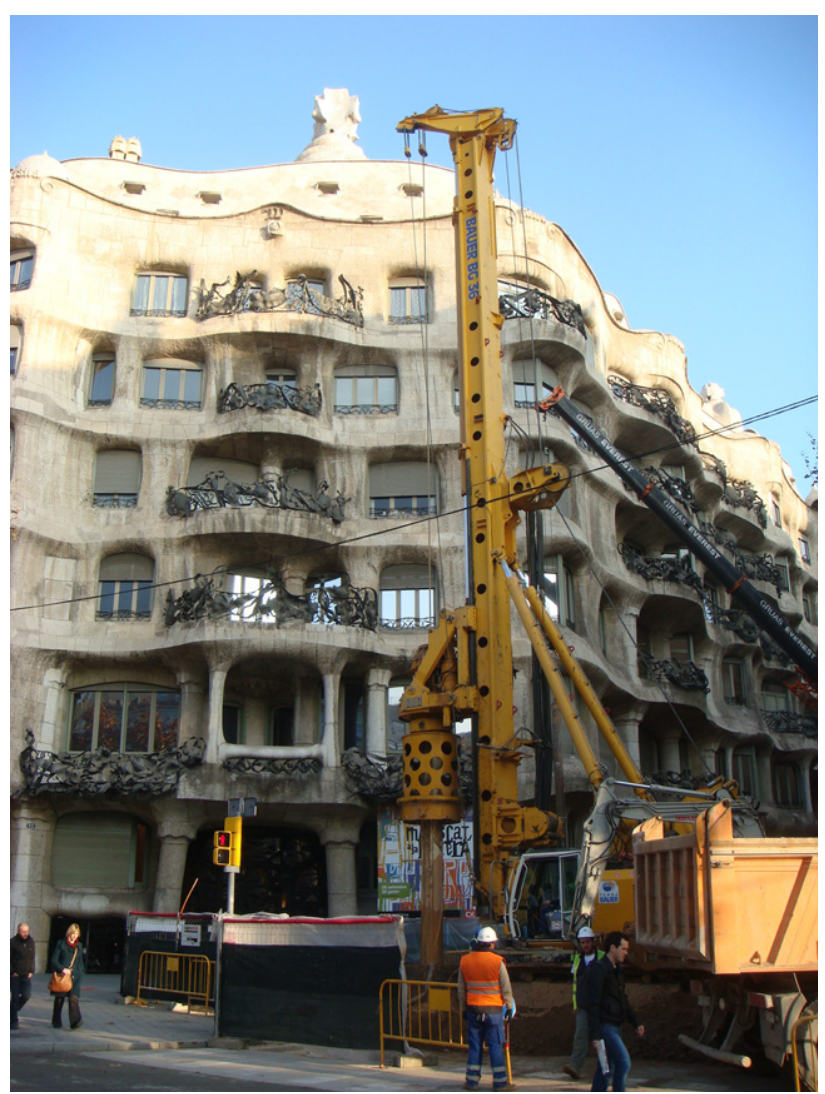

Fig. 14. Pile wall construction next to Casa Milà

paper to the geometry and soil properties of the Sagrada Familia site yielded curve C in Fig. 5 and curve B in Fig. 7. They show the same trend as the base case. It should be noted that, for the two different geometries, there is a stiffness ratio threshold below which the efficiency is quite constant. That threshold corresponds to $\Pi_{4}=E_{\mathrm{s}} R / E_{\mathrm{w}} A_{\mathrm{w}} \approx 0 \cdot 01$. Increasing the wall thickness and therefore reducing $\Pi_{4}$ below that value does not improve efficiency.

Numerical analyses of the tunnel-wall interaction were carried out in the design phase, using Flac software, and later in the validation stage, using Plaxis (Pinto-Candia, 2011). The displacement field was found to be very sensitive to the constitutive model adopted. During the design phase, an elasto-plastic Mohr-Coulomb model was adopted but, during the validation stage, it was assumed that stiffness at small strains should be taken into account to predict reasonable values. Therefore, the hardening soil model with small strains (Benz et al., 2009) implemented in Plaxis was adopted as a base model for the validation process.

A range of parameters for the soils in the area was obtained from laboratory tests and in-situ information from the project (Pinto-Candia, 2011; Rodríguez-Escribano \& Blanco-Zorroza, 2012). Experience from previous laboratory campaigns (Barrera, 2002) was also taken into account. Table 1 presents one set of parameters used in the analyses of the Sagrada Familia site at the validation stage. To simplify the calculations, only four materials were considered: fill, Quaternary silty clay, Tertiary sand and Tertiary clay (both Pliocene). Within the Quaternary unit, apart from the fill, it was convenient to adopt a single material because of the heterogeneity of the gravel and sand lenses that were mixed with clay and silt (Fig. 11). A 2D FE mesh, $140 \mathrm{~m}$ wide and $60 \mathrm{~m}$ high was used for the validation stage in order to separate boundaries from the zone of the wall and the tunnel. The water table was assumed to be at $15 \mathrm{~m}$ depth. 
Table 1. Parameters of the hardening soil with small-strain model implemented in Plaxis

\begin{tabular}{|c|c|c|c|c|c|c|c|c|c|c|}
\hline Material & $\begin{array}{l}\gamma_{\text {unsat: }} \\
\mathrm{kN} / \mathrm{m}^{3}\end{array}$ & $\begin{array}{c}\gamma_{\text {sat }}: \\
\mathrm{kN} / \mathrm{m}^{3}\end{array}$ & $\begin{array}{l}E_{50}^{\text {ref. }} \\
\mathrm{MPa}\end{array}$ & $\begin{array}{l}E_{\text {oed }}^{\text {ref }} \\
\mathrm{MPa}\end{array}$ & $\begin{array}{l}E_{\mathrm{ur}}^{\mathrm{ref}} \\
\mathrm{MPa}\end{array}$ & $\begin{array}{c}c^{\prime}: \\
\mathrm{kPa}\end{array}$ & $\begin{array}{c}\phi^{\prime}: \\
\text { degrees }\end{array}$ & $\gamma_{0 \cdot 7}$ & $\begin{array}{c}G_{0}: \\
\mathrm{MPa}\end{array}$ & $R_{\text {inter }}$ \\
\hline Fill & 19 & 20 & 19 & $15 \cdot 2$ & 57 & 10 & 28 & $10^{-4}$ & $61 \cdot 5$ & $0 \cdot 67$ \\
\hline $\begin{array}{l}\text { Quaternary silty } \\
\text { clay }\end{array}$ & $19 \cdot 3$ & 21 & 30 & 24 & 90 & 50 & 28 & $8 \cdot 5 \times 10^{-5}$ & 121 & $0 \cdot 67$ \\
\hline Pliocene sand & $20 \cdot 5$ & $20 \cdot 5$ & 30 & 24 & 90 & 20 & 35 & $10^{-4}$ & 112 & $0 \cdot 67$ \\
\hline Pliocene clay & $20 \cdot 5$ & $20 \cdot 5$ & 30 & 24 & 90 & 80 & 28 & $8.5 \times 10^{-5}$ & 254 & $0 \cdot 67$ \\
\hline
\end{tabular}

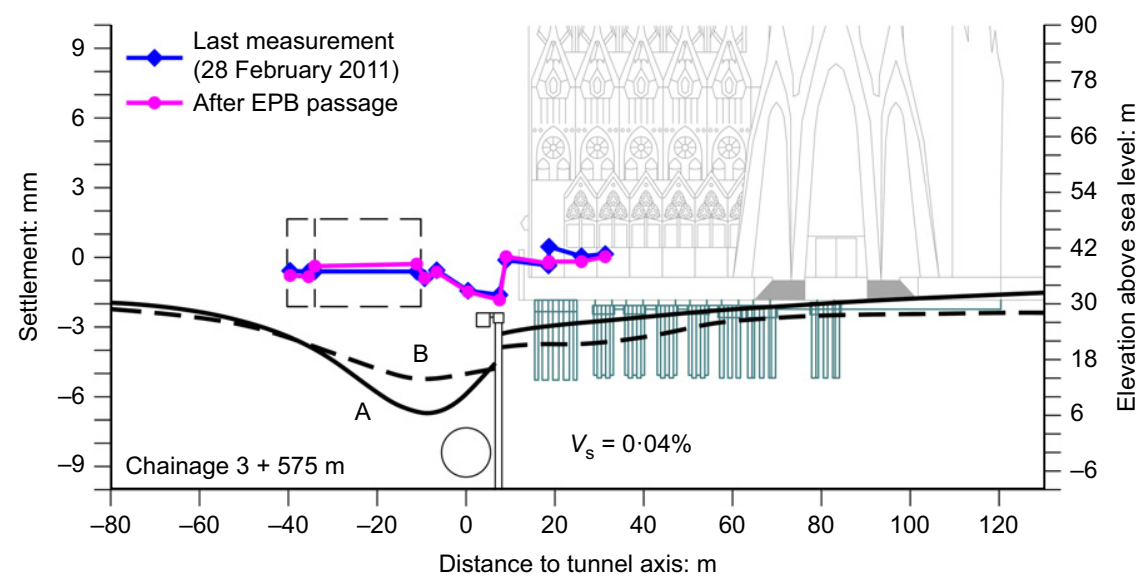

Fig. 15. Measured and computed vertical displacements at chainage $3+575 \mathrm{~m}$ in the Sagrada Familia basilica due to the tunnel excavation. Computed settlements correspond to a volume loss of $0 \cdot 5 \%$, whereas measured ones represented a volume loss of about $0 \cdot 04 \%$. Curves A and B respectively show computed settlements without and with considering external loads from the monument and other buildings

In Table $1, R_{\text {inter }}$ refers to the wall-soil interface conditions; that is, the interface strength is this coefficient multiplied by the soil shear strength. A typical value of 0.67 , as suggested by Brinkgreve et al. (2016), was used in most of the analyses.

The key parameter in all analyses was the volume loss, which is difficult to predict in advance. A conservative value was thus adopted, ranging from $0 \cdot 5 \%$ to $1 \cdot 0 \%$. However, the experience gained during construction and before reaching the basilica was very positive, with measured ground losses consistently well below $0 \cdot 1 \%$.

\section{Monitoring and wall effectiveness}

The area affected by the tunnel was heavily instrumented. Soil displacements were much lower than the values predicted at the design stage, partly because the scenarios considered in terms of volume loss were too conservative. Fig. 15 illustrates one of the cross-sections at chainage $3+575 \mathrm{~m}$, including measured and computed settlements using different approaches. The figure shows the basilica in the background and the location of the protecting wall. The settlement measurements corresponding to the EPB passage and to long-term conditions are presented. Two of the settlement troughs computed during the validation stage are also shown (curves A and B): they correspond to a volume loss of $0.5 \%$ and to drained conditions, thus the computed displacements can be compared to long-term measurements, well after the passage of the EPB. The two curves highlight the factors that may influence the displacement profile and hence wall efficiency. Curve A in Fig. 15 does not consider external loads due to the Sagrada Familia and the buildings on the other side of the street (Carrer de Mallorca). Curve B takes into account a distributed load of $200 \mathrm{kPa}$ from the basilica and $120 \mathrm{kPa}$ from the buildings on the other side of the street.
The stress history of the soil and the particular geometry of the site become important factors in defining settlement troughs, particularly when a constitutive model that takes stress history into account is used. Some of the buildings in front of the basilica have underground parking; considering such a geometry resulted in an unloading of the soil, leading to an overconsolidated state. Considering the load from the basilica changed the shape of the displacement field as well, and provoked a normally consolidated state in the soil below. Depending on these aspects, the maximum settlement in the area of the street could be closer to the Sagrada Familia side or to the side of the front buildings - behaviour clearly departing from the elastic (constant modulus) assumption. A key aspect when designing this type of wall is that they usually protect heavy monuments; the building load must therefore be taken into account for an accurate analysis.

Efficiency of the piles as defined by equation (10) may change depending on the settlement trough obtained. In addition, undrained/drained conditions have an influence. However, a minimum efficiency of about $40-50 \%$ was found for all cases, suggesting that, at least, the pile wall reduced the settlement by a factor of two.

Figure 15 indicates that the measured movements were about $2 \mathrm{~mm}$ above the tunnel, with smaller values behind the wall. In fact, most movements were below the range of accuracy of the measuring instruments used. The volume loss corresponding to the measured settlement trough shown in Fig. 15 is about $0 \cdot 04 \%$.

\section{Impact on historic buildings}

The impact of the tunnel on Sagrada Familia and Casa Milà was negligible. This was predicted by the design and validation analyses, in contrast to the apocalyptic predictions from basilica officials. Damage to sensitive buildings was 
evaluated by means of damage diagrams (Boscardin \& Cording, 1989; Burland et al., 2001; Pickhaver, 2006). Such charts define the impact of tunnelling on a building in a simplified manner, as a function of the deflection ratio or angular distortion (gradient of the settlement trough) and horizontal deformation. This paper focused on how settlement troughs change due to a protective wall. However, there is evidence that such walls are also very efficient in terms of reducing horizontal strain (Bilotta \& Russo, 2011). In particular, at the Sagrada Familia site and in the Casa Milà area, when the protective wall was included in the analyses, excavation of the tunnel with a volume loss of $0.5 \%$ resulted in negligible impact on the structures.

\section{CONCLUSIONS}

The paper described the use of a wall interposed between a tunnel to be excavated and an existing building to be protected - a condition that frequently arises in urban environments. This idea has been successfully used in practical applications, particularly in the city of Barcelona during the excavation of a tunnel next to the Sagrada Familia basilica and Casa Milà, both constructions having World Heritage status.

This paper first presented a simplified procedure, based on linear elasticity, to estimate settlement troughs for the particular geometry of a tunnel and an adjacent stiff wall. The simplicity of the formulations allowed the problem to be defined in terms of a few dimensionless parameters, which helps in the understanding of the key aspects of the wall-tunnel interaction. From this simplified procedure, it was possible to define the following criteria.

- The settlement trough becomes non-symmetric with respect to the tunnel axis due to the presence of a wall. Generally, maximum displacement is shifted away from the wall.

- Displacement of the wall is controlled by the movement of the wall tip. To reduce settlements, the wall tip should have negligible movement and thus it must be located at an adequate depth. It is suggested that the wall vertical length $(L)$ should be at least $C+1 \cdot 5 D(C$ being the tunnel cover and $D$ the tunnel diameter).

- There is a limiting value of wall stiffness $\left(E_{\mathrm{w}} A_{\mathrm{w}}\right)$, above which the efficiency of the wall does not increase. That limiting value is defined by the condition $\Pi_{4}=E_{\mathrm{s}} R / E_{\mathrm{w}} A_{\mathrm{w}} \approx 0 \cdot 01$.

- The wall efficiency, defined in equation (10), does not depend on the ground loss.

- Within the range of values of wall-tunnel distance (d) considered in the analyses, the value of $d$ does not substantially change the wall efficiency.

The simplified analysis presented in this paper does not remove the need for a full $\mathrm{FE}$ analysis when studying a real problem. However, it helps in the understanding of the working mechanism of tunnel-wall interactions and defines the main variables that control the behaviour of such systems.

The paper also described a case study involving the protection of two historic structures from the impact of tunnelling in the city of Barcelona. The case study was used to complement the application of the simplified procedure. The simplified method was also compared with results from $\mathrm{FE}$ analyses. The results yielded the following new perspectives in the design of protective walls.

- When using FE analysis and elasticity, field displacements are very sensitive to the boundaries. If the lower boundary is too close to the wall tip, efficiencies may be unrealistic.
- When using advanced constitutive models for soil behaviour, efficiencies can be very different depending on many factors. Efficiencies of about $90 \%$ have been reported (for a hardening soil model (Bilotta \& Russo, 2011)), but values as low as $40 \%$ were calculated here for the hardening soil model with small strains and the geometry considered. The important load of the Sagrada Familia basilica, its piled foundation and the excavation of underground parking for some buildings nearby distorted the classical Gaussian-shaped settlement trough. However, most of the computed efficiencies for the analyses considered were above $50 \%$.

The measured movements were very small, close to the accuracy of the measuring instruments, thanks to the low ground loss generated by the EPB machine operation and the soil stiffness. The use of protective walls constitutes, however, a good technique in general to substantially reduce the impact of tunnelling on sensitive structures. Even in cases where movements are very small, the wall provides a guarantee to reduce the risk of severe damage should an unexpected problem arise during tunnel excavation (e.g. a malfunction in the EPB system). Therefore, the use of wall barriers should always be considered when sensitive heritage buildings may be affected by the impact of tunnelling in urban environments.

\section{ACKNOWLEDGEMENTS}

The authors participated as geotechnical advisors during the construction phase of the project. They acknowledge with thanks the support and contributions of the engineers involved, in particular those from Adif (Spanish Railway Administration), Sacyr-Cavosa-Scrinser (contractor), the technical assistance and design team (Intecsa-InarsaCensa) and the EPB online external control unit (Sener). Thanks also go to Cristian de Santos and Andrés Pinto at Universitat Politècnica de Catalunya, who collaborated on some of the FE analyses of the Sagrada Familia site.

\section{NOTATION}

$A_{\mathrm{w}}$ cross-sectional area of wall per unit length

$b$ pile diameter

$C$ tunnel cover

c distance from soil surface to force application point within half-space

$c^{\prime}$ soil cohesion

$D$ tunnel diameter

$d$ distance from tunnel centre to wall axis

$E_{\text {oed }}^{\text {ref }} \quad$ reference value of oedometric modulus

$E_{\mathrm{s}} \quad$ Young's modulus of soil

$E_{\mathrm{ur}}^{\mathrm{ref}} \quad$ reference value of unloading-reloading modulus

$E_{\mathrm{w}} \quad$ Young's modulus of wall

$E_{50}$ Young's modulus of soil at $50 \%$ of ultimate load

$E_{50}^{\text {ref }}$ reference value of the soil Young's modulus at $50 \%$ of the failure load

$F$ force per unit length inside a half-space

$G_{0} \quad$ maximum shear elastic modulus

$H$ depth of tunnel spring line

$I_{\mathrm{w}}$ second moment of inertia of wall section per unit length

$L$ height of wall

$N_{j} \quad$ axial force per unit length in wall segment $j$

$n$ number of segments in wall

$\mathcal{P}$ dimensionless soil-wall interaction force

$P_{\mathrm{i}} \quad$ soil-wall interaction forces (per unit length)

$P_{\mathrm{A}}, \ldots, P_{\mathrm{F}} \quad$ soil-wall interaction forces (per unit length)

$P_{\text {tip }} \quad$ reaction at wall tip (per unit length)

$R$ tunnel radius 
$R_{\text {inter }}$ interface shear strength coefficient (multiplied by the soil shear strength to compute the interface shear strength)

$s$ spacing between pile centres in a row of piles

$s_{\text {bw }}$ ground surface settlement just behind wall

$s_{\text {ref }}$ reference greenfield ground surface settlement

$U_{z} \quad$ dimensionless vertical soil displacement

$u_{n} \quad$ vertical displacement of the wall tip (positive downwards)

$u_{z} \quad$ vertical soil displacement (positive downwards)

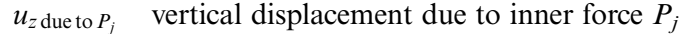
(per unit length)

$u_{z \text { structural wall }}$ vertical displacement of wall as a structural element

$u_{z \text { tunnel }} \quad$ vertical displacement due to tunnel excavation $u_{0}$ arbitrary vertical displacement (positive downwards)

$V_{\mathrm{s}} \quad$ volume loss: area of settlement trough over tunnel cross-section

$w$ horizontal coordinate where settlement is zero

$X$ horizontal dimensionless coordinate

horizontal coordinate

$x_{M}$ horizontal coordinate for Melan's problem

$Z$ vertical dimensionless coordinate

vertical coordinate

$z_{\mathrm{M}} \quad$ vertical coordinate for Melan's problem

$\gamma_{\text {sat }}$ specific weight of saturated soil

$\gamma_{\text {unsat }}$ specific weight of unsaturated soil

$\gamma_{0.7}$ shear strain when elastic shear modulus is $70 \%$ of the maximum shear modulus

$\varepsilon \quad$ equivalent ground loss parameter

$\varepsilon_{0} \quad$ average ground loss, volume loss

$\eta$ efficiency of wall

$v$ Poisson's ratio of soil

$\Pi_{1}, \ldots, \Pi_{4} \quad$ dimensionless variables controlling the theoretical problem

$\rho_{1}$ distance from force application point to the point considered in the half-space

$\rho_{2}$ distance from the image point of the force application point, above the soil surface, to the point considered in the half-space

$\phi^{\prime} \quad$ soil friction angle

\section{REFERENCES}

Alonso, E. E. \& Ledesma, A. (2015). High speed tunnel crossing of downtown Barcelona: design, construction and performance. In Geotechnical engineering for infrastructure and development: proceedings of the XVI European conference on soil mechanics and geotechnical engineering. Volume 2: infrastructure (eds M. G. Winter, D. M. Smith, P. J. L. Eldred and D. G. Toll), pp. 223-228. London, UK: ICE Publishing.

Attewell, P. B., Yeates, J. \& Selby, A. R. (1986). Soil movements induced by tunneling and their effects on pipelines and structures. Glasgow, UK: Blackie.

Barrera, M. (2002). Estudio experimental del comportamiento hidro-mecánico de suelos colapsables. $\mathrm{PhD}$ thesis, Universitat Politècnica de Catalunya, Barcelona, Spain (in Spanish).

Benz, T., Vermeer, P. A. \& Schwab, R. (2009). A small-strain overlay model. Int. J. Num. Analyt. Methods in Geomech. 33, No. 1, 25-44.

Bilotta, E. (2008). Use of diaphragm walls to mitigate ground movements induced by tunnelling. Géotechnique 58, No. 2, 143-155, http://dx.doi.org/10.1680/geot.2008.58.2.143.

Bilotta, E. \& Russo, G. (2011). Use of a line of piles to prevent damages induced by tunnel excavation. J. Geotech. Geoenviron. Engng ASCE 137, No. 3, 254-262.

Bilotta, E. \& Stallebrass, S. E. (2009). Prediction of stresses and strains around model tunnels with adjacent embedded walls in overconsolidated clay. Comput. Geotech. 36, No. 6, 1049-1057.

Bilotta, E., Paolillo, A., Russo, G. \& Aversa, S. (2017). Displacements induced by tunnelling under a historical building. Tunn. Undergr. Space Technol. 61, No. 1, 221-232.

Boscardin, M. D. \& Cording, E. J. (1989). Building response to excavation-induced settlement. J. Geotech. Engng ASCE 115, No. $1,1-21$.
Brinkgreve, R. B. J., Kumarswamy, S. \& Swolfs, W. M. (2016). Plaxis 20162 D manual. Delft, the Netherlands: Plaxis bv.

Burland, J. B., Standing, J. R. \& Jardine, F. M. (eds) (2001). Building response to tunnelling. Case studies from the Jubilee Line Extension, London. Volume 1, projects and methods. Volume 2, case studies, Ciria Special Publication 200. London, UK: CIRIA and Thomas Telford.

Chen, L. T., Poulos, H. G. \& Loganathan, N. (1999). Pile responses caused by tunnelling. J. Geotech. Geoenviron. Engng 125, No. 3, 207-215.

Di Mariano, A., Gens, A., Gesto, J. M. \& Schwartz, H. (2007). Ground deformation and mitigating measures associated with the excavation of a new Metro line. In Geotechnical engineering in urban environments: proceedings of the 14th European conference on soil mechanics and geotechnical engineering (eds V. Cuellar, E. Dapena, E. Alonso, J. M. Echave, A. Gens, J. L. de Justo, C. Oeto, J. M. Rodriguez-Ortiz, C. Sagaseta, P. Sola and A. Soriano), vol. 4, pp. 1901-1906. Rotterdam, the Netherlands: Millpress Science.

Gens, A., Di Mariano, A., Gesto, J. M. \& Schwartz, H. (2006). Ground movement control in the construction of a new metro line in Barcelona. In Geotechnical aspects of underground construction in soft ground (eds K. J. Bakker, A. Bezuijen, W. Broere and E. A. Kwast), pp. 389-395. London, UK: Taylor \& Francis.

Katzenbach, R., Vogler, M., Kurze, S. \& Dunaevskiy, R. (2011). Enhanced geotechnologies for the protection of World Heritage properties. In Proceedings of the 15th European conference on soil mechanics and geotechnical engineering: geotechnics of hard soils - weak rocks (eds A. Anagnostopoulos, M. Pachakis and C. Tsatsanifos), vol. 3, pp. 1859-1864. Amsterdam, the Netherlands: IOS Press.

Kitiyodom, P., Matsumoto, T. \& Kawaguchi, K. (2005). A simplified analysis method for piled raft foundations subjected to ground movements induced by tunnelling. Int. J. Num. Analyt. Methods Geomech. 29, No. 15, 1485-1507.

Lee, K. M., Kerry Rowe, R. \& Lo, K. Y. (1992a). Subsidence owing to tunnelling. I. Estimating the gap parameter. Can. Geotech. J. 29, No. 6, 929-940.

Lee, K. M., Kerry Rowe, R. \& Lo, K. Y. (1992b). Subsidence owing to tunnelling. II. Evaluation of a prediction technique. Can. Geotech. J. 29, No. 6, 941-954.

Lee, Y. J. \& Basset, R. H. (2006). A model test and numerical investigation on the shear deformation patterns of deep wall-soiltunnel interaction. Can. Geotech. J. 43, No. 12, 1306-1323.

Lee, Y. J. \& Basset, R. H. (2007). Influence zones for 2D pilesoil-tunnelling interaction based on model test and numerical analysis. Tunn. Undergr. Space Technol. 22, No. 3, 325-342.

Loganathan, N. \& Poulos, H. G. (1998). Analytical prediction for tunneling-induced ground movements in clays. J. Geotech. Geoenviron. Engng ASCE 124, No. 9, 846-856.

Mair, R. J. (2008). Tunnelling and geotechnics: new horizons. Géotechnique 58, No. 9, 695-736, http://dx.doi.org/10.1680/ geot.2008.58.9.695.

Mair, R. J. \& Taylor, R. N. (1997). Bored tunnelling in the urban environment, theme lecture. In Proceedings of the 14th European conference on soil mechanics and foundation engineering, Hamburg, 6-12 September 1997, pp. 2353-2385. Rotterdam, the Netherlands: Balkema.

Melan, E. (1932). Der Spannungszustand der durch eine Einzelkraft im Innern beanspruchten Halbscheibe. Z. Angew. Math. Mech. 12, No. 6, 343-346 (in German).

Mu, L., Huang, M. \& Finno, R. J. (2012). Tunnelling effects on lateral behaviour of pile rafts in layered soil. Tunn. Undergr. Space Technol. 28, No. 3, 192-201.

Oteo, C. S., de la Fuente, P. \& de Assis, S. (2007). Jet-grouting walls as protection to the buildings near urban tunnels. In Geotechnical engineering in urban environments: proceedings of the 14th European conference on soil mechanics and geotechnical engineering (eds V. Cuellar, E. Dapena, E. Alonso, J. M. Echave, A. Gens, J. L. de Justo, C. Oeto, J. M. Rodriguez-Ortiz, C. Sagaseta, P. Sola and A. Soriano), vol. 3, pp. 1504-1508. Rotterdam, the Netherlands: Millpress Science.

Peck, R. B. (1969). Advantages and limitations of the observational method in applied soil mechanics. Géotechnique 19, No. 2, 171-187, http://dx.doi.org/10.1680/geot.1969.19.2.171. 
Pickhaver, J. A. (2006). Numerical modelling of building response to tunnelling. $\mathrm{PhD}$ thesis, University of Oxford, Oxford, UK.

Pinto-Candia, A. E. (2011). Pantallas laterales como medida de mitigación de movimientos inducidos por la excavación de túneles. MEng thesis, Universitat Politècnica de Catalunya, Barcelona, Spain (in Spanish).

Potts, D. M. \& Addenbrooke, T. I. (1997). A structure's influence on tunnelling-induced ground movements. Proc. Instn Civ. Engrs - Geotech. Engng 125, No. 2, 109-125, http://dx.doi. org/10.1680/igeng.1997.29233.

Potts, D. M. \& Zdravković, L. (2001). Finite element analysis in geotechnical engineering: application. London, UK: Thomas Telford.

Pujades, E., Vázquez-Suñé, E., Carrera, J., Vilarrasa, V., De Simone, S., Jurado, A., Ledesma, A., Ramos, G. \& Lloret, A. (2014). Deep enclosures versus pumping to reduce settlements during shaft excavations. Engng Geol. 169, No. 4, 100-111.

Pujades, E., Vázquez-Suñé, E., Culí, L., Carrera, J., Ledesma, A \& Jurado, A. (2015). Hydrogeological impact assessment by tunnelling at sites of high sensitivity. Engng Geol. 193, No. 2, $421-434$.

Rodríguez-Escribano, R. \& Blanco-Zorroza, A. (2012). Estudio de la interacción entre las obras del templo de la Sagrada Familia y las del túnel de alta velocidad entre las estaciones de Sants y La Sagrera, en Barcelona. Rev. Obras Púb. 159, No. 3529, 7-30 (in Spanish).

Sagaseta, C. (1987). Analysis of undrained soil deformation due to ground loss. Géotechnique 37, No. 3, 301-320, http://dx.doi. org/10.1680/geot.1987.37.3.301.

Sneddon, I. N. (1951). Fourier transforms. New York, NY, USA: McGraw-Hill.

Telles, J. C. F. \& Brebbia, C. A. (1981). Boundary element solution for half-plane problems. Int. J. Solids Struct. 17, No. 12, $1149-1158$.

Verruijt, A. \& Booker, J. R. (2000). Complex variable analysis of Mindlin's tunnel problem. In Developments in theoretical geomechanics. The John Booker memorial symposium (eds D. W. Smith and J. P. Carter), pp. 3-22. Rotterdam, the Netherlands: Balkema. 